\title{
Effects of Ochratoxin a on Broiler Leukocytes
}

\section{Author(s)}

Moura MA ${ }^{1}$

Machado $\mathrm{CH}^{2}$

Porfírio $\mathrm{LC}^{3}$

Freire $\mathrm{RB}^{4}$

Med. Vet., Ms., FIOCRUZ.

Med. Vet., PhD., Adj. Professor at DMCV/ IV-UFRRJ.

Med. Vet., PhD., Adj. Professor at IV-UfES.

4 Post-Doctor, Animal Immunotoxicology $\mathrm{Ms}, \mathrm{PhD}$, Adj. Professor at DBA/B-UFRRJ.

\section{Mail Address}

Moura MA

Avenida Embaixador Abelardo Bueno, 3000

(1/306), Barra da Tijuca

22.775-040 - Rio de Janeiro, RJ

Phone: $+55+21$ 9873-1677

Email: m.a.moura@ig.com.br

\section{Keywords}

Broilers, hematology, mycotoxin, ochratoxin A.

\section{ABSTRACT}

This study evaluated alterations in the qualitative cellular profile of leukocytes caused by the administration of low doses of ochratoxin-A (OTA) in poultry. Sixty chicks were separated in three experimental groups: control, PBS-treated and OTA-treated. Blood smears from all birds were analyzed three and six hours post-treatment. Differential leukocyte counting demonstrated that OTA reduced the percentage of lymphocytes and eosinophils and significantly increased the number of heterophils and monocytes.

\section{INTRODUCTION}

Mycotoxins are metabolites from fungi of heterogeneous nature and with different pharmacological effects. They may be injurious to animal health, resulting in reduced performance and pathologic lesions. In the past years, mycotoxicosis have been matter of concern worldwide due to losses caused to the poultry industry (Santin et al., 2001).

Mycotoxicosis occur in variable intensities. The levels of natural contamination are generally not high enough to cause open manifestations. Besides, animals may have different susceptibility to mycotoxins, depending on genetic, physiological and environmental factors (Freire, 1996).

Ochratoxin A (OTA) is a mycotoxin produced by Aspergillus ocraceus, the first fungi from which it has been isolated and after which it is named. It is also produced by many other Aspergillus and Penicillium species (Studer-Kohr et al., 1995). Recent studies showed that OTA is produced by $A$. niger (Stander, et al. 2000). Although all Aspergillus species produce OTA, $A$. carbonarius produces the highest quantities of this mycotoxin (Pitt et al., 2002; Pitt, 2000).

Ochratoxins are derived from isocoumarin and L-b-phenylalanine, and are classified as pentapeptides. The nephrotoxic effect of OTA has been shown in many animal species, although sensitivity is variable among them (reviewed by Abarca et al., 2001). OTA also has teratogenic, immunosuppressive, carcinogenic and hepatotoxic effects (reviewed by Scudamore, 1996).

Mycotoxicosis affect poultry industry by decreasing the growth rate and worsening both feed conversion and reproductive efficiency (Jelinek et al., 1989). In most situations, mycotoxicosis are caused by ingestion of low quantities of fungal metabolites, and result in evidenced decrease in farm productive performance and in the appearance of non-specific alterations such as subcutaneous hemorrhage and immunosuppression (Giambrone et al., 1985).

In rats, age-specific pathologic lesions were not caused by OTA, although younger animals showed higher clinical sensitivity (Dortant et al., 2001). The kidney is the main and primary organ affected by OTA 
toxicity. The immune system is probably not the main target of OTA toxicity, a fact that was evidenced in producing birds (Huff et al., 1988).

OTA acts essentially in the proximal renal tubules, inhibiting the enzyme phosphoenolpyruvate carboxylase, which is a lipid peroxidant, and it alters the structural and functional renal ability to metabolize calcium (Betina, 1989). Morphologically, the kidney shows atrophy and sclerosis of the proximal tubules. Functionally, tubular functions are reduced, as well as the kidney's ability to concentrate urine (Pitt, 2000).

In broilers, more than $2 \mathrm{mg}$ OTA/ $\mathrm{kg}$ of feed increased the relative weight of the liver, kidney, spleen, pancreas, proventriculus, gizzard and heart, and significantly reduced the relative weight of the Bursa of Fabricius (Gibson etal., 1989; Huff et al., 1988). Increased mortality and poorer feed conversion efficiency were reported in adult birds when 4mg OTA/ $\mathrm{kg}$ diet was present (Gibson et al., 1989). Birds have also shown anemia with decreased number of red blood cells and lower hemoglobin concentration (Huff et al., 1988).

In birds, the ingestion of OTA causes lesions in the hematopoietic system, and hematopoiesis is suppressed. It also causes myelotoxicity and immunosuppressive effects on the thymus, bursa of Fabricius, spleen and lymph nodes (reviewed by Bennett, 2003), reducing the production of blood cells and promoting hemoglobin decrease, together with the appearance of leukopenia and lymphopenia in broilers (Corrier, 1991; reviewed by Bennett, 2003). Dwivedi \& Burns (1984) observed such effects in doses higher than $2 \mathrm{ppm}$, but they were more evident in dosages of $4 \mathrm{ppm}$.

Leszkowicz \& Castegnaro (1995) and a review from Scudamore (1996) described the LD50 of ochratoxin as a function of the animal sensitivity and administration route, and determined $3.3 \mathrm{mg} / \mathrm{kg}$ body weight as the $50 \%$ lethal dose for broilers when administered orally.

Considering that the blood cells are responsible for the cellular and humoral defenses of the organism, a reduction or suppression of these cells by toxic substances results in increased susceptibility of birds to viral and/or bacterial infections. The present study reports the occurrence of changes in the qualitative leukocyte profile, evaluated in blood smears, as a result from the administration of low doses of OTA in broiler birds.

\section{MATERIAL AND METHODS}

One-day-old male chicks from the HIYIELD/RESENDE strain were provided by Granja Sadia/Minas Gerais,
Brazil. Sixty chicks were separated in three experimental groups comprising 20 animals each: Group 1 - control; Group 2 - treated intraperitoneally with 0,1 mL PBS; and Group 3 - treated with $0.04 \mathrm{mg}$ OTA $/ \mathrm{kg}$ of body weight. Purified and crystalline OTA (Sigma Chemicals Co., St. Louis, USA) was diluted in $0,1 \mathrm{~mL}$ PBS and intraperitoneally administered. The dose was equivalent to approximately $1 / 100$ from the DL50 established by Leszkowicz \& Castegnaro (1995).

Commercial broiler diets were given to the birds. The diets were tested by fluorescence liquid-phase chromatography and were negative for the presence of OTA.

Blood samples were taken by cardiac puncture from 10 birds in each group at three and six hours posttreatment, and heparin was used as anticoagulant. Samples were taken to the laboratory under refrigeration as recommended by Hawkey \& Dennet (1989).

Identification and proportions of leukocytes were determined in Giemsa-stained blood smears using 100x magnification according to Jain (1993).

Data were analyzed by chi-square test at $5 \%$ probability level to assure that they were normally distributed, as suggested by Gomes (1990). They were then submitted to analysis of variance and Snedecor's $F$ test was used to compare means at significance levels of $5 \%$ and $1 \%(\alpha=0.05$ and $\alpha=0.01)$.

\section{RESULTS AND DISCUSSION}

The objective of the present study was to evaluate the acute toxic effect resulting from a single exposure to OTA. According to a previous report (Freire, 1996), intraperitoneal administration of mycotoxins induces a short time exposure to the biologically active compound, due to its pK and to the fact that the circulatory metabolism of one-day-old chicks is very accelerated. In periods longer than six hours, the birds were completely recovered and no hematologic effects attributable to the exposure to mycotoxin could be observed. The birds were healthy until slaughter and no pathological alterations indicative of intoxication were seen.

The variation in the percentage of basophils was less than $1 \%$ in all evaluated groups, at 3 and 6 hours after treatment. Since normal birds may have percentage values varying between 0 and $6 \%$ for basophils (McNulty, 1991; Harrisd, 1991; Jain, 1993), alterations seen for this cell type in the different groups were considered non-statistically different. Conversely, the circulating eosinophil population varied significantly 
in the birds exposed to OTA. There was an increase equivalent to $136.95 \%$ in the first three hours, followed by a decrease equivalent to $53.84 \%$ at 6 hours when compared to the PBS-inoculated group (Table 1). It is worth noting that the mean percentage of circulating eosinophils reported for non-inoculated animals was $2.6 \%$ and $4.6 \%$ at three and six hours of observation. Considering that the observed values are much higher than the mean variation ( 0 and $6 \%$ ) that is accepted for normal birds (Harrisd, 1991; Jain, 1993), this might indicate important clinical-hematological alterations resulting from the presence of parasites or IL5-inducing allergens, methodological error, or yet management stress. The first alternatives were discarded and the reproducibility of the results was very high. Therefore, it was assumed that the restraint conditions to which the newly hatched birds were submitted to have somethow affected the mean number of circulating eosinophils. The high numeric difference found between the non-inoculated animals and those inoculated with PBS or OTA, it is, the marked decrease in the number of circulating eosinophils, suggests that the percentage of circulating granulocytes might indicate important alterations due to bird handling. Therefore, the differences found between the toxinadministered and the vehicle-administered groups indicated that the variation resulted from the inoculation stress. The cell percentage decrease was exacerbated as a result from the stress caused by the mycotoxin, mainly in the first three hours after exposure. The recovery seen in the following three hours was due to the metabolization and consequent unavailability of mycotoxin, and hence did not represent a specific effect of the mycotoxin on the population of circulating eosinophils. On the other hand, although OTA may cause mielotoxicity when ingested and result in neutropenic leukopenia in broilers chickens (Chang et al., 1979), both heterophils and monocytes were markedly increased when compared to the animals that were not submitted to any treatment (Table 1). Although the increasing trend in the number of phagocytes is suggestive of stress resulting from inoculation, OTA-treated birds had a significant increase in the number of heterophils and monocytes when compared to the vehicle-treated birds. There was a significant mean increase in the number of heterophils in OTA-treated birds compared to the other experimental groups, at three and six hours (Table 1). The monocytes, on the other hand, increased 200\% in the first three hours and showed a tendency to regularization in the following three hours, so that the values were 1.23 times higher than the mean of the vehicle-treated group at six hours after inoculation. Such results corroborate other previous reports that suggest that OTA promote an inflammatory chemotaxis in the inoculation site and a consequent increase in the number of heterophils (McNulty, 1991; Rupley, 1999; Feldman et al., 2000).

\begin{tabular}{|c|c|c|c|c|c|}
\hline Cells & Groups & 3 hours & SD & 6 hours & SD \\
\hline Basophils & $\begin{array}{c}\text { Control } \\
\text { PBS } \\
\text { OTA }\end{array}$ & $\begin{array}{l}0.6 \\
0.6 \\
0.7\end{array}$ & $\begin{array}{l}1.26 \\
0.70 \\
0.95\end{array}$ & $\begin{array}{l}0.4 \\
0.5 \\
0.4\end{array}$ & $\begin{array}{l}0.52 \\
0.71 \\
0.70\end{array}$ \\
\hline Eosinophils & $\begin{array}{c}\text { Control } \\
\text { PBS } \\
\text { OTA }\end{array}$ & $\begin{array}{l}2.6 \\
4.6 \\
6.3\end{array}$ & $\begin{array}{l}1.07 \\
3.16 \\
2.63\end{array}$ & $\begin{array}{l}4.6 \\
5.2 \\
2.8\end{array}$ & $\begin{array}{l}2.50 \\
1.87 \\
1.14\end{array}$ \\
\hline Heterophils & $\begin{array}{c}\text { Control } \\
\text { PBS } \\
\text { OTA }\end{array}$ & $\begin{array}{l}56.5 \\
50.8 \\
71.3\end{array}$ & $\begin{array}{c}7.38 \\
6.25 \\
10.04\end{array}$ & $\begin{array}{l}61.1 \\
63.9 \\
83.2\end{array}$ & $\begin{array}{l}5.45 \\
5.09 \\
3.43\end{array}$ \\
\hline Lymphocytes & $\begin{array}{c}\text { Control } \\
\text { PBS } \\
\text { OTA }\end{array}$ & $\begin{array}{l}33.1 \\
34.0 \\
12.8\end{array}$ & $\begin{array}{l}6.44 \\
4.64 \\
5.43\end{array}$ & $\begin{array}{c}27.0 \\
24.4 \\
6.2\end{array}$ & $\begin{array}{l}3.92 \\
4.03 \\
1.23\end{array}$ \\
\hline Monocytes & $\begin{array}{c}\text { Control } \\
\text { PBS } \\
\text { OTA }\end{array}$ & $\begin{array}{c}7.2 \\
5.3 \\
10.6\end{array}$ & $\begin{array}{l}2.70 \\
3.27 \\
6.35 \\
\end{array}$ & $\begin{array}{l}6.9 \\
6.0 \\
7.4 \\
\end{array}$ & $\begin{array}{l}1.79 \\
1.94 \\
2.46 \\
\end{array}$ \\
\hline
\end{tabular}

Although the mean lymphocyte percentage was higher in both treated groups than in the noninoculated animals, a tendency to lymphopenia in the birds inoculated with mycotoxin was seen during the first six hours after inoculation. In the first three hours, the number of quantified lymphocytes in the vehicletreated animals was 4.72 times higher than the mean number recorded for non-treated animals. The birds inoculated with OTA, on the other hand, showed a mean value 1.78 times higher than the mean of the non-inoculated control group. Therefore, the stress induced uniquely by vehicle inoculation, in the first three hours, caused an increase 2.66 times higher than the increase attributed to OTA (Table 1). On the other hand, the reported immunosuppressor effect that induces lymphopenia in the thymus, bursa of Fabricius, spleen and lymph nodes (Chang \& Hamilton, 1980; Corrier, 1991; Abarca, 2001; Bennett, 2003) would only occur after some time, and would be more probable in situations of chronic intoxication. Since there were no marked differences between the two inoculated 
groups after six hours, no conclusions can be drawn about such aspect because only one exposure was performed and the birds were evaluated for a short period of time. Therefore, the significant decrease seen in the first three hours suggest that, due to the great mycotoxin availability (100\%), a direct toxic effect might have occurred on the populations of circulating lymphocytes (mostly $\mathrm{T}$ helper lymphocytes), probably because it is related to the bcl surface determinants, or through the activation of caspases and consequent induction of cellular death by apoptosis (Freire, 1996).

\section{CONCLUSIONS}

The effects of the exposure of one-day-old broiler chicks to low doses of ochratoxin A correspond to a marked decrease in the percentage of circulating lymphocytes and a significant increase in the percentage of inflammatory cells (monocytes and heterophils). This prevents that newly hatched birds mount adequate inflammatory responses against the different pathogens from the environment, and also undoubtedly affects the ability to respond to vaccines.

\section{REFERENCES}

Abarca ML, Accensi F, Bragulat MR, Cabanes FJ. Current importance of ochratoxin A-producing Aspergillus spp. Journal of Food Protection 2001; 64(6):903-6.

Bennett JW, Klich M. Mycotoxins. Clinical microbiology 2003; 16(3): 497-516.

Betina V. Mycotoxins-chemical, biological and environmental aspects. Amsterdan (NL): Elsevier, 1989. p. 325-421.

Chang CF, Hamilton PB. Impairment of phagocytosis in chicken monocytes during aflatoxicosis. Poultry Science 1979; 58:562-566.

Chang CF, Huff WE, Hamilton PB. Leukocytopenia induced in chickens by dietary ochratoxin A. Poultry Science 1979; 58:555558.

Corrier DE. Mycotoxicosis: Mechanisms of immunosuppression. Veterinary Immunology and Immunopathology 1991; 30:73-87.

Dortant PM, Peters-Volleberg GWM, Van Louverem H, Marquardt RR, Speijers GJA. Age-related differences in the toxicity of ochratoxin $A$ in female rats. Food and Chemical Toxicology 2001; 39:55-56.

Dwived $\mathrm{P}$, Burns RB. Pathology of ochratoxicosis $A$ in young broiler chicks. Research in Veterinary Science 1984; 36:92-103.

Feldman BF, Zilkl JG, Jain, NC. Schalm's veterinary hematology. 5 ed. Philadelphia (PA): Lippincott Willians \& Wilkins; 2000. p.597739.
Freire RB. Micotoxinas e Resposta imune. In: Perspectiva Latinoamericana . Rio de Janeiro: UFRRJ Editora; 1996. $261 \mathrm{p}$.

Giambrone JJ, Diener UL, Davis ND, Panagula VS, Horff FJ. Effects of aflatoxin on young turkeys and broiler chickens. Poultry Science 1985; 64(3):1678-1684.

Gibson RM, Bailey CA, Kubena LF, Huff WE, Harvey RB. Ochratoxin $A$ and dietary protein. Effects on body weight, feed conversion, relative organ weight, and mortality in three-week-old broilers. Poultry Science 1989; 68(12):1658-63.

Gomes FP. Curso de Estatística Experimental. 13. ed. Piracicaba(SP): Livraria Nobel; 1990; 468 p.

Harrisd J. Pet avian medicine. Veterinary Clinics of North America: Small Animal Practice 1991; 21(6):1166-1967.

Hawkey CM, Dennett TB. Atlas of comparative veterinary hematology. London: Wolf Publishing, 1989. 365p.

Huff WE, Kubena LF, Harvey RB. Progression of ochratoxicosis in broiler chickens. Poultry Science 1988; 67(8):1139-46.

Jain NC. Essentials of Veterinary Hematology. Philadelphia (PA): Lea \& Febiger; 1993. 417p

Jelinek CF, Pohland AE, Wood GE. Worldwide occurrence of mycotoxins in foods and feeds - an update. Journal of Association of Official Analytical Chemists 1989; 72:223-230.

Leszokoswicz AP, Castegnaro M. Struture, toxixites et metabolisme de L'ochratoxine A. René de microbiologie alimentarie 1995;45 (45):86-98

McNulty MS. Chicken anemia agent: a review. Avian Pathology 1991; 20:215-223

Pitt Jl, Basílico ML, Abarca ML, Lopez C. Mycotoxins and toxigenic fungi, Medical Mycology 2002; 38(supplement L):41-46

Pitt TL. Toxigenic fungi: Which are important? Medical Mycology 2000; 38 (supplement L):17-22.

Rupley AE. Manual de clínica aviária. São Paulo (SP): Editora Roca;1999. 582p.

Santin E, Maiorka A, Zanella I, Magon L. Mycotoxin of Fusarium ssp in commercial poultry. Ciência Rural 2001; 31(1):185-190.

Scudamore KA. Ochratoxin A in animal feed-effects of processing Food additives and contaminants 1996; 13 (Supplement):39-42.

Stander MA, Bornscheneuer UT, Henke E, Steyr PS. Screening of commercial hydrolases for degradation of Ochratoxin A. Journal of Agriculture and Food Chemists 2000; 48:5736-5739.

Studer-Kohr I, Dietrich DR, Schlatter J, Schlatter C. The Occurrence of Ochratoxin A in Coffee. Food and Chemical Toxicology 1995; 33(5):341-355. 